Hernández-Acosta, E., Banuelos, J., \& Trejo-Aguilar, D. (2021).

Revisión: Distribución y efecto de los hongos micorrízicos

en el agroecosistema de café. Revista de Biología Tropical,

69(2), 445-461. DOI 10.15517/rbt.v69i2.42256

DOI $10.15517 /$ rbt.v69i2.42256

REVISIÓN

\title{
Revisión: Distribución y efecto de los hongos micorrízicos en el agroecosistema de café
}

\author{
Elizabeth Hernández-Acosta ${ }^{1}$ \\ Jacob Banuelos ${ }^{2}$ \\ Dora Trejo-Aguilar ${ }^{2 *}$
}

1. Universidad Autónoma Chapingo. Departamento de Suelos, Carretera Federal México-Texcoco Km 38.5, C.P. 56230 Texcoco, México; ehernandeza@chapingo.mx

2. Universidad Veracruzana, Facultad de Ciencias Agrícolas, Lomas del Estadio s/n, Zona Universitaria, 91000, Xalapa, Veracruz, México; jbanuelos@uv.mx, doratrejo@gmail.com (*Correspondencia).

Recibido 16-VI-2020. Corregido 05-I-2021. Aceptado 10-II-2021.

\section{ABSTRACT \\ Distribution and effect of mycorrhizal fungi in the coffee agroecosystem: A review}

\begin{abstract}
Introduction: Coffee is a highly mycotrophic plant, its interaction with arbuscular mycorrhizal fungi has been studied among different tropical countries. The majority of the published works indicates that coffee is benefited from the mycorrhizal association, where the AMF confers protection against pathogens and diseases, increases water absorption, as well as it increases the adaptation of the plant at transplant from nurseries to the main plantation. Objective: A review was made where we summarized and analyze the research reports of AMF with coffee from at least the past 10 years, focused on AMF global species distribution, nutritional benefits of the association and interaction with pathogens. Methods: We retrieved available bibliographic data from coffee producer countries in public databases. We considered published works from 2000 to 2019, nevertheless, we included classic papers on the topic, outside that period, mainly the ones performed in Brazil since 1986. We organized the number of reported species per country, we look for synonyms, grouped them by family, genera and species. The reports that only reported genera or where ambiguous were used as reference but not considered for the final analysis. We summarized the reports of the benefits of the AMF interaction in coffee, as well as pathogen tolerance. Results: The collected data shows that there are more than $100 \mathrm{AMF}$ species associated with coffee, which represents more than a third part of the total of reported species worldwide. We found that Colombia has the highest richness, but it also has the highest number of published reports. Conclusions: This information shows the benefits of the incorporation of AMF to coffee plantation programs, because these fungi are a key element in coffee plant nutrition, nevertheless, the coffee variety should be considered when introducing AMF, as not all associations has been efficient.
\end{abstract}

Key words: biodiversity; coffee; generalist species; rhizosphere; symbiosis.

El café es una planta que se cultiva en diversas zonas tropicales del mundo, en México, el $90 \%$ de la superficie es bajo sombra (Moguel \& Toledo 1999), Colombia (Cardona-Calle
\& Sadeghian-Kh, 2005), Costa Rica (FilhoVirginio et al., 2015), Nicaragua, El Salvador (Méndez, Bacon, Olson, Morris \& Shattuck, 2013), Perú (Julca-Otiniano, Alarcón-Águila, 
Alvarado-Huamán, Borjas-Ventura, \& CastroCepero, 2018) y Venezuela (Farreras, 2018). Este sistema agroforestal permite conservar la biodiversidad del suelo (bacterias, hongos, protozoarios, nemátodos, macrofauna como lombrices e insectos) aves, y mamíferos (Manson, Hernández-Ortiz, Gallina, \& Mehltreter, 2008); capturar carbono, participar en los ciclos biológicos y conservar el suelo y el agua (Ruelas-Monjardín, Nava-Tablada, Cervantes \& Barradas, 2014). El cultivo de café se considera de bajo impacto ambiental (GarcíaAlvarado, Díaz-Zorrilla, Castañeda-Hidalgo, Lozano-Trejo \& Pérez-León, 2017). Aunque la siembra a pleno sol permite obtener rendimientos superiores en comparación con el sistema bajo sombra, $443 \mathrm{~kg} \mathrm{ha}^{-1}$ contra $515 \mathrm{~kg} \mathrm{ha}^{-1}$ (Campanha et al., 2004), requiere un aporte constante de fertilizantes y plaguicidas (Arias, Heredia-Abarca, Sosa, \& Fuentes-Ramírez, 2012). De acuerdo con una revisión realizada por Meena et al. (2020), el uso prolongado de agroquímicos afecta negativamente la biodiversidad del suelo, la sostenibilidad de la agricultura y la inocuidad de los alimentos a largo plazo.

La presencia y el estado de micorrización de las raíces de los cafetos fue observada por vez primera en 1897 (Saggin-Júnior \& Siqueira, 1996), y se ha demostrado desde entonces que esta simbiosis tiene un efecto importante en el desarrollo de esta especie. En los cafetales, los hongos micorrízicos arbusculares (HMA), destacan en la microbiota del suelo debido a que incrementan la sobrevivencia de la planta al momento del trasplante (Trejo-Aguilar et al., 2011), la sanidad vegetal (França, de Freitas, dos Santos, Grazziotti, \& Andrade, 2016), el vigor y el desarrollo de las mismas, traducido en un incremento en rendimientos (HernándezAcosta, Trejo-Aguilar, Ferrera-Cerrato, RiveraFernández, \& González-Chávez, 2018). La inoculación de HMA en plántulas de café durante la etapa de semillero y vivero, es una práctica agrícola que permite obtener plantaciones comerciales exitosas (Pérez-Lavalle, Bolívar-Anillo, \& Díaz-Pérez, 2017).
Debido a las pérdidas económicas ocasionados por la roya de café, en los últimos años se han liberado diversas variedades de café resistentes al patógeno. Una alternativa en los programas de replantación de fincas es la micorrización en la producción de plántulas, sin embargo; no todas las variedades responden de la misma manera a la micorrización, (Fonseca et al., 2019; Hernández-Acosta, Trejo-Aguilar, Ferrera-Cerrato, \& Rivera-Fernández, 2020).

El uso de inoculantes micorrízicos comerciales se ha generalizado, pero se ha comprobado que no todas las especies de hongos micorrízicos tienen el mismo efecto en las plantas de café (Trejo-Aguilar et al., 2011) y que las prácticas de manejo en el cultivo repercuten sobre la eficiencia de esta simbiosis.

Los trabajos publicados sobre este tipo de respuesta enfatizan la necesidad de ubicar a nivel mundial las especies micorrízicas asociadas al cultivo de café y el efecto que tienen en el agroecosistema. El objetivo de esta revisión fue resumir y analizar la investigación que existe sobre esta asociación en los últimos 10 años, aunque fue necesario incluir los trabajos pioneros realizados en Brasil que datan de hace más de 25 años.

\section{MATERIALES Y MÉTODOS}

Búsqueda de información: Se realizó una búsqueda de estudios referentes a especies de plantas de café y hongos micorrízicos en las plataformas de Google Scholar, Web of Science, Wiley, Springer Link. El intervalo de búsqueda seleccionado fue de el 2009 hasta el 2019, con la finalidad de tener mayor cantidad de especies reportadas con la nomenclatura más reciente (Stürmer, Bever, \& Morton, 2018). Se utilizaron combinaciones de las siguientes palabras clave en español e inglés, respectivamente: Hongos micorrízicos arbusculares (HMA), micorrizas, Arbuscular mycorrhizal fungi (AMF), mycorrhizae, café (coffee), Coffea arabica, México (Mexico), Colombia, Brasil (Brazil), Perú (Peru), India, Etiopía (Ethiopia), Yemen, Egipto (Egypt), Arabia Saudita (Saudi Arabia), Indonesia, Tailandia 
(Thailand), Laos y Venezuela; así como de cada género de Glomeromycota. Además, se utilizó la combinación de operadores boléanos: AND, OR, NOT para incluir palabras clave y excluir países o términos en la búsqueda.

Análisis de los resultados: Los resultados se recuperaron manualmente para descartar aquellos sin identificación taxonómica de HMA, o sin relación con la revisión. Se realizó una tabla de especies por país con ayuda de los paquetes Limma (Ritchie et al., 2015), Venn Diagram (Chen, 2018), SunburstR (Bodstock, Rodden, \& Russel, 2017) para R y la herramienta online de Bioinformatic Evolutionary Genomics (http://bioinformatics.psb.ugent.be/ webtools/Venn/), se generaron los diagramas de Venn y dos figuras, una de especies generales y otra de distribución mundial, se utilizó el programa en línea Datawrapper (https:// www.datawrapper.de/). Con el propósito de unificar el nombre de las especies se consultó Index Fungorum, para detectar sinonimias; también se consultó el listado de especies de la página www.amf-phylogeny.com (última actualización 30 de marzo del 2019) por Arthur Schüßler. Para la nomenclatura y clasificación, se siguió el trabajo de Redecker et al. (2013).

\section{RESULTADOS}

Distribución de los HMA asociados al cultivo de café: El análisis sobre la identificación basada en caracteres morfológicos mostró que existen más de 100 especies de HMA que se asocian a las plantas de café en diferentes países del mundo (Fig. 1). De acuerdo con datos de la lista de especies actualizada en febrero del 2020 (http://www.amf-phylogeny. com/amphylo_species.html) existen 334 especies reportadas de HMA, por lo que el número de especies asociadas al café representa la tercera parte del total de las especies existentes. Estas 100 especies están distribuidas en 20 géneros, 9 Familias, 5 órdenes y 3 clases, de acuerdo con la Clasificación de Redecker et al. (2013).

En la Fig. 2 se muestra que las especies están distribuidas principalmente en 3 clases: Glomeromycetes (90), Archaeosporomycetes

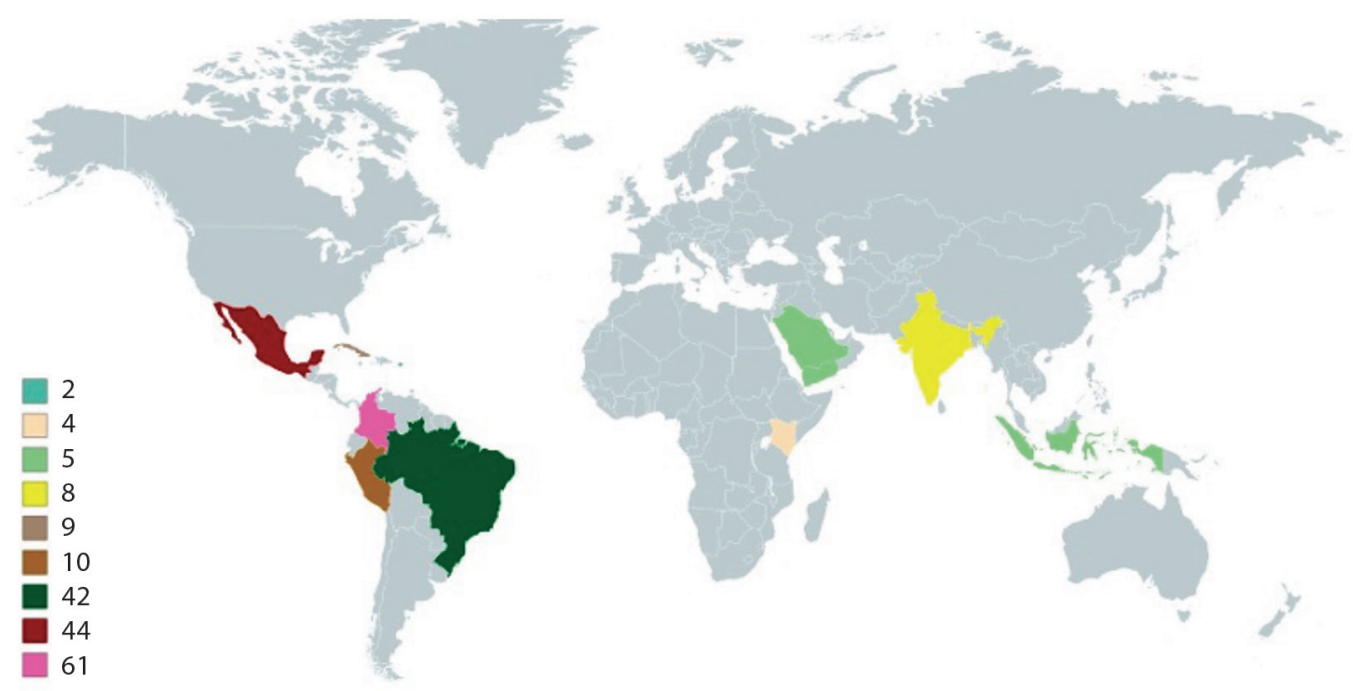

Fig. 1. Países que reportan estudios taxonómicos basados en las características morfológicas de la micorriza arbuscular (generada con www.datawrapper.de). Cada país está representado por un color que indica el número de especies reportadas y encontradas en esta revisión.

Fig. 1. Countries that report taxonomic studies based on morphological characteristics (image generated with www. datawrapper.de). Each country is represented by a color that specifies the number of reported and found species in this review. 


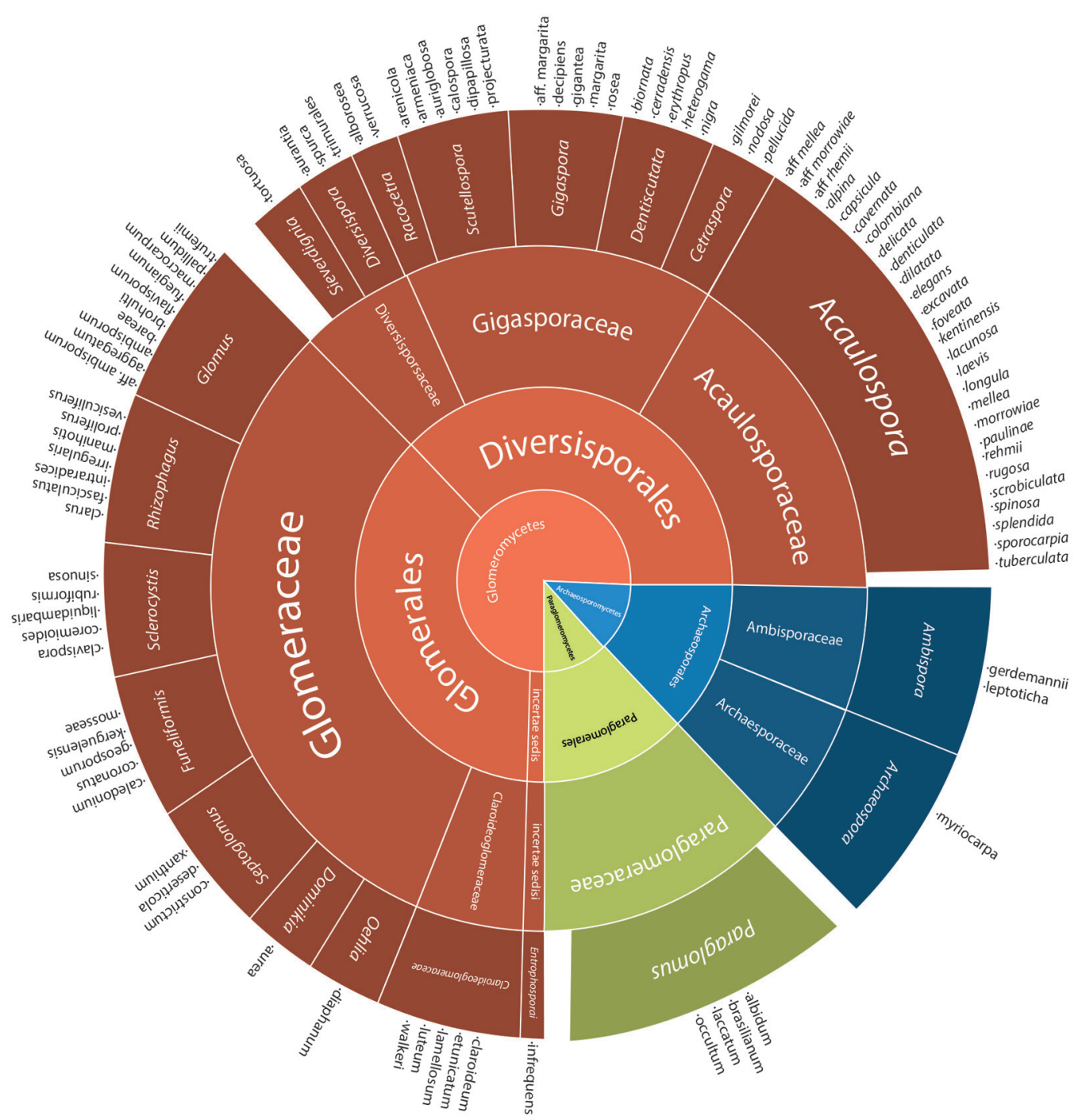

Fig. 2. Resumen de las 99 especies asociadas a la rizósfera de plantas café, incluyendo orden, clase, familia, género y especie (realizado con el paquete sunburstR).

Fig. 2. Summary of the 99 species associated to the coffee rhizosphere, including class, family, genera and species (image done with sunbustR).

(5) y Paraglomeromycetes (4); siendo las familias Gigasporaceae (19), Acaulosporaceae (31) y Glomeraceae (32), las que concentran más especies (ya que se encontró un total de 99 especies incluidas en otras familias).

Los datos presentados en las Fig. 3A y Fig. $3 \mathrm{~B}$, son un concentrado del número de especies únicas por país y el número de especies compartidas entre países. Brasil es el país con la mayor cantidad de trabajos reportados en el agroecosistema (48, Saggin-Júnior \& Siqueira, 1996), y fue uno de los primeros en realizar la identificación molecular de los HMA en café (Colozzi-Filho \& Nogeira-Cardoso, 2000).

En esta revisión aun no es posible explicar el significado ecológico de la presencia de las especies de HMA, ya que los reportes se han realizado en diferentes países, variedades 

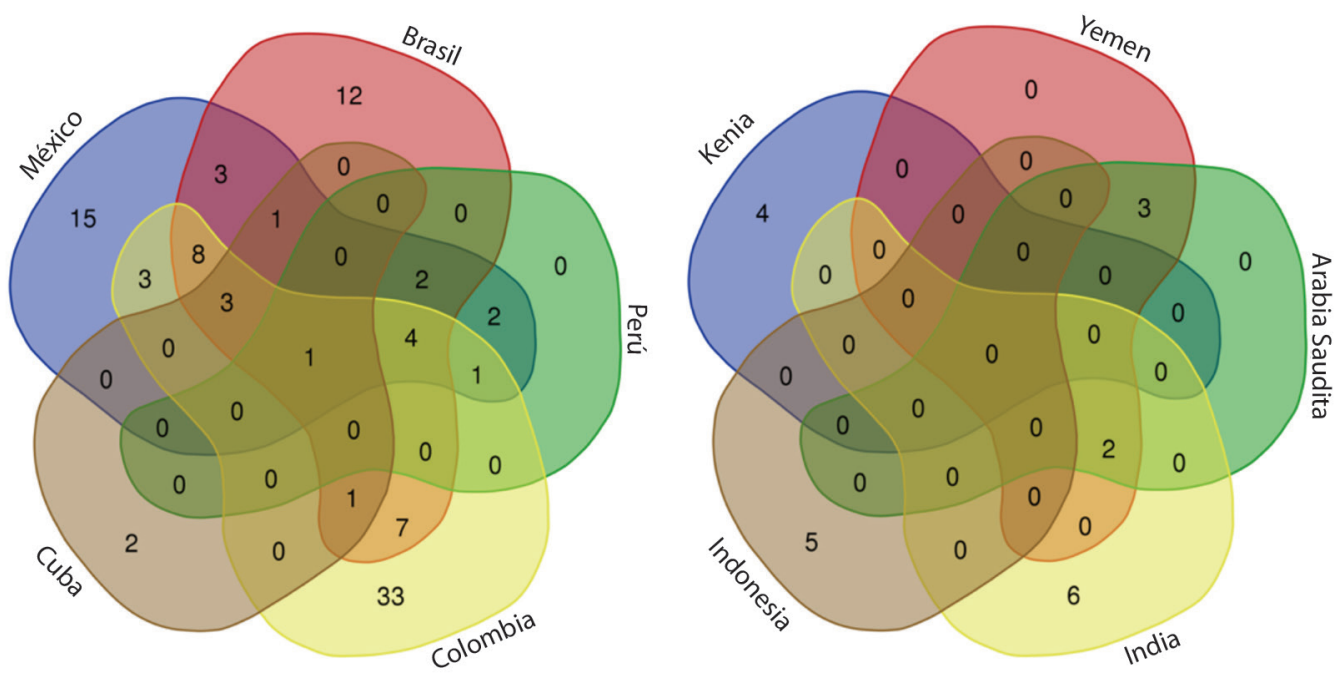

Fig. 3. Diagrama de Venn, compara la presencia de especies de hongos micorrízicos en países productores de café de A. América, B. África y Asia (Generados con el paquete Venn Diagram para R).

Fig. 3. Venn diagram that compares the arbuscular mycorrhizal fungi occurrence in coffee producer countries of A. America, B. Africa and Asia (generated with the R package VennDiagram).

de café y métodos de muestreo; sin embargo, proporciona información, sobre cuales especies se asocian con mayor frecuencia al café y sus perspectivas de uso en la producción de inoculantes para este cultivo.

Las familias con el mayor número de especies asociadas al café: Acaulosporaceae, Gigasporaceae y Glomerace (Fig. 2) son los grupos, frecuentemente presentes, cuando se relacionan con características edáficas (Cardoso et al., 2020), en ecosistemas naturales (Maia, Passos, Silva, Oehl, \& Assis, 2020) y la intensidad del uso del suelo (Ontivero et al., 2020).

El género Acaulospora, con el mayor número de especies reportadas asociadas a este cultivo, es un género de HMA que frecuentemente se encuentra en $\mathrm{pH}$ ácidos (Oehl et al., 2010), donde el café también se desarrolla adecuadamente (Posada, Heredia-Abarca, Sieverding, \& Sánchez, 2012).

El sistema de producción de café con sus diferentes métodos de manejo, alberga una alta diversidad de especies vegetales utilizadas como sombra, por otra parte, en el mundo se cultivan más de 65 variedades de café que se dividen en dos grupos principales: Arábica y Robusta, y a partir de estas derivan múltiples cultivares (Fernández, De Guglielmo, \& Menéndez, 2010) lo que significa que dentro de esos agroecosistemas hay un acervo genético, cuyos hospederos influyen en la comunidad de los hongos micorrízicos (Kivlin, Hawkes, \& Treseder, 2011), la diversidad de especies vegetales podría explicar la amplia diversidad de especies de los HMA, asociados al café en el mundo como se muestra en este análisis (Fig. 2). Por otra parte, los factores edáficos y climáticos (Stevens et al., 2020), participan en la selección de las especies de los HMA.

\section{Especies de HMA en América Latina:} El género con mayor número de especies asociadas al café es Acaulospora con 23 spp.; agroecosistemas, como el forestal, también reportan mayor presencia de este género (Vieira et al., 2019; Solís-Rodríguez, Ramos-Zapata, Hernández-Cuevas, Salinas-Peba \& Guadarrama, 2020).

Los países con mayor número de especies "únicas" (asociadas a café por país, pero endémicas) fueron Brasil con 12 (SagginJúnior \& Siqueira, 1996; Colozzi-Filho \& 
Nogeira-Cardoso, 2000; Stürmer \& Siqueira, 2006; França, de Freitas, dos Santos, Grazziotti, Andrade, 2016; Cogo et al., 2017; Moreira, França, Grazziotti, Leal, \& Silva, 2019), México con 15 (Trejo-Aguilar et al., 2011; Arias et al., 2012; Posada et al., 2012; Pérez-Luna, Álvarez-Solís, Hernández-Cuevas, \& Sánchez-Roque, 2016; Posada, Sánchez, HerediaAbarca, \& Sieverding, 2018; Herrera-Monroy, Castro-Brindis, Pérez-Moreno, \& Valdés-Velarde, 2019; Bertolini, Montaño, Salazar, Chimal, \& Varela, 2020) y Colombia con 33 (Posada et al., 2012; Posada et al., 2018), además de ser los países con más trabajos publicados. En Perú hay 10 reportes (Vallejos-Torres, Arévalo, Iliquin, \& Solís, 2019), en Cuba 9 (Sánchez et al., 2000) y en Puerto Rico, 2 (Lebrón, Lodge, \& Bayman, 2012).

En la Fig. 3A se observa que la especie con mayor presencia en la rizósfera de café en seis países de América Latina es Glomus aggregatum, (Rhizophagus irregularis), esta especie es ecológicamente conocida como generalista (Rajeshkumar, Thomas, Gupta, \& Gopal, 2015) y pese a mostrar promoción de crecimiento en las plantas (Veeramachaneni \& Ramachandrudu, 2020) no necesariamente es la especie más eficiente. En un trabajo clásico, Saggin-Júnior \& Siqueira (1996) mostraron que las especies consideradas como las más eficientes para café son Gigaspora margarita y Glomus etunicatum, pese a presentar una baja densidad relativa (1 y $5 \%$, respectivamente) en la población nativa de hongos micorrízicos.

El trabajo realizado por Hernández-Acosta et al. (2018), mostró que en las variedades de café (Garnica, Catimor, Caturra y Catuaí) inoculadas solo con Rhizophagus aggregatus vs un consorcio compuesto por Glomus claroides, Glomus diaphanum y Glomus albidum, el consorcio puede inducir un incremento en biomasa de hasta cuatro veces más que una sola especie. Trejo-Aguilar et al. (2011) identificaron que un consorcio de 10 especies era más eficiente que uno de cuatro. Es evidente que hay especies generalistas que pueden asociarse con plantas de café en casi todas las regiones del mundo (Fig. 3), pero conocer cuáles especies de HMA están asociadas al cultivo de café y qué combinaciones son más eficientes de acuerdo con la variedad de la planta, servirá como referencia en la producción de biofertilizantes micorrízi$\cos$ (Ortaş, 2020).

Especies de HMA en África y Asia: El mayor número de especies en África y Asia se encuentran en la familia Acaulosporaceae (32 especies), al igual que en América. India es el país con mayor número de reportes 8 (Bhattacharya \& Bagyaraj, 2002), seguido de Yemen (Mahdhi, Tounekti, Al-Turki, \& Khemira, 2017), Arabia Saudita (Mahdhi et al., 2017) e Indonesia con 5 (Arif et al., 1999) y Kenia solo reporta 4 (Jefwa et al., 2009). No se comparte ninguna especie entre Arabia Saudita, India, Indonesia, Kenia y Yemen. La India tiene 8 , el mayor número de especies. Indonesia y Kenia tienen especies únicas dentro de cada país, mientras que, Arabia Saudita y Yemen tienen 3 especies idénticas.

Cuatro de cinco países de África, Asia y América comparten dos especies: Rhizophagus intraradices y Funeliformis mosseae, consideradas como generalistas (Reid \& Emery, 2017). Sin embargo, algunos trabajos sugieren que estas especies tienen gran capacidad de establecimiento por su alta capacidad reproductiva, lo que indica que algunas especies nativas más eficientes podrían ser desplazadas (Fester, 2013; Reid \& Emery, 2017).

La alta diversidad de especies asociadas al cultivo de café puede indicar una dependencia de la simbiosis, independientemente de la región geográfica, altitud, suelo, microclima, topografía y prácticas de manejo. De Carvalho et al. (2012) consideran que el café podría representar un "hot spot" de diversidad por la heterogeneidad de los agroecosistemas donde se cultiva.

\section{DISCUSIÓN}

Dinámica poblacional de los HMA en los agroecosistemas cafetaleros: Los agroecosistemas cafetaleros albergan una población de HMA diversa y abundante (Bertolini et al., 
2020). Este trabajo muestra algunos de esos datos condensados. La alta diversidad de HMA en el sistema cafetalero puede depender del hospedero (Camargo-Ricalde, Montaño-Arias, De la Rosa-Mera, \& Montaño-Arias, 2012), aunque los factores bióticos y abióticos del sitio podrían determinar la sucesión de las especies fúngicas (Lu et al., 2019).

La incorporación de la micorriza como un elemento biotecnológico del sistema cafetalero, deberá valorar el desempeño fúngico y grado de eficiencia de la micorrización (Noriega et al., 2014; Hernández-Acosta et al., 2018). En la mayor parte de los cafetales, la tecnificación y monocultivo no están presentes, pues estos factores podrían afectar la funcionalidad, viabilidad y poblaciones de los hongos micorrízicos nativos (Trejo-Aguilar, Barois \& Sangabriel-Conde, 2016). Este sistema de cultivo permite la persistencia natural de la diversidad de HMA, pudiendo ser determinante en su eficiencia como inoculante. Trejo-Aguilar et al. (2011) da un ejemplo de esta idea, en plantas de café "Garnica", un consorcio de HMA proveniente de sitios con un alto nivel de tecnificación, muestra una baja riqueza y eficiencia en el crecimiento y sobrevivencia al trasplante; esto contrasta con un consorcio proveniente de fincas con un nivel medio de alteración, cuya eficiencia es significativamente mayor a la de suelos altamente tecnificados, incrementando la sobrevivencia al trasplante hasta un $80 \%$ más.

El sistema agroforestal presenta una mayor riqueza de especies. Tan solo en México, TrejoAguilar et al. (2011) reportaron 10 especies para sistemas de producción con un $50 \%$ de sombra, en contraste con cuatro en un cafetal sin sombra. En Etiopía, De Beenhouwer et al. (2015) reportaron 31 OTUs (Unidad operacional taxonómica) en el sistema forestal y solo seis en un sistema con menor regulación de la sombra. En Brasil, Prates-Júnior et al. (2019) estudió tres sistemas de manejo: Fragmento forestal, agroecológico y convencional, en donde encontró que el manejo agroecológico era similar al bosque natural y con índices de diversidad más altos que el manejo convencional, con una tendencia similar a los trabajos realizados en México y Etiopía.

En México, el sistema de café bajo sombra tiene un aporte continuo de nutrientes provenientes del estrato arbóreo, principalmente de leguminosas como Leucaena leucocephala, Inga vera, Erythrina poeppigiana (Youkhana \& Idol, 2011; Garza-Lau, Maldonado-Torres, Álvarez-Sánchez, \& Torres-Rivera, 2020). Esta diversidad de leguminosas permite que los suelos de las fincas no requieran altos aportes de nutrientes (Roskoski, 1982). El microclima que se mantiene dentro del sistema agroforestal y el contenido de materia orgánica crea un ambiente óptimo para la sobrevivencia de microorganismos benéficos entre los que destacan los HMA.

Importancia de la micorrización en el cultivo de café: En México, a principios de los noventa se ubicó a la planta de café como un excelente hospedero de HMA, dado que se encontraba de manera natural en los sistemas productivos bajo sombra; se reportó también que varias especies fúngicas eran nativas y que la eficiencia simbiótica podría ser alta o baja dependiendo del género al cual pertenecía el hongo que habitaba la raíz (Hernández-Acosta, Ferrera-Cerrato, \& Trejo-Aguilar, 1996). Datos similares reportaron para Colombia, Parra, Sánchez, \& Sieverding (1990), quienes encontraron los géneros de hongos micorízicos Entrophospora colombiana, Glomus manihotis y Acaulospora myriocarpa como especies nativas que utilizaron como inóculos en plántulas de café.

La práctica de inoculación micorrízica es una alternativa necesaria en el café (Tristão, Andrade, \& Silveira, 2006), por diversas razones: a) los cafeticultores realizan tareas como la desinfección del suelo o sustrato donde sembrarán las semillas de café (Barrer, 2009), eliminando microorganismos, entre ellos los hongos micorrízicos arbusculares; b) el periodo de estancia de aproximadamente 12 meses de la planta en vivero, bajo riegos constantes y con baja fertilización; c) el trasplante predispone a la plántula al estrés, la planta debe contar con 
un sistema biológico que le permita tolerar los cambios del ambiente, condición dada por la asociación micorrízica (Gaitán, Villegas, Rivillas, Hincapié, \& Arcilla, 2011; ValverdeLucio et al., 2020); d) la asociación micorrízica estimula la ramificación de la raíz, aumenta su superficie y por lo tanto su área de absorción (Camargo-Ricalde et al., 2012).

Por otra parte, es común que el cultivo de café se establezca en suelos andosoles, que se caracterizan por retener el fósforo, los HMA incrementan la absorción de este nutrimento por vía simbiótica hasta un $44 \%$ en comparación con plantas de café no inoculadas, por lo que la planta requiere de la simbiosis para la traslocación de este elemento (HernándezAcosta et al., 2020).

La presencia de la micorriza en las plantas de café favorece la disminución del suministro de fertilizantes, lo cual impacta positivamente en la economía del cafeticultor, pero también existe un impacto ecológico y ambiental positivo, permite la sustentabilidad del agroecosistema al otorgar servicios ambientales como la captura de carbono, protección del suelo, recarga de acuíferos, mejorar la calidad del aire entre otros (Ruelas-Monjardín et al., 2014).

La planta de café es un hospedero de los hongos micorrízicos arbusculares, esta simbiosis se da de manera natural en el suelo, las propiedades de mayor importancia son el $\mathrm{pH}$ (5.7 a 6.6), baja concentración de fósforo (de 5.3 a $18.4 \mathrm{mg} \mathrm{kg}^{-1}$ ) (Bertolini et al., 2020) y de sales (Peroza \& Perez, 2010), humedad (60\%), y la presencia de especies de hongos micorrízicos arbusculares, estas posibilitan el éxito de la infección del hongo en las plantas de café (Jaramillo, 2011; Ortiz-Acevedo, OsorioVega, Echeverri-Gómez, González-Murillo, \& Medina-Sierra, 2015). Arévalo (2018) reporta que una abundancia en raíces incrementa el porcentaje de colonización y en consecuencia una mayor esporulación; aunque esto no es una regla, Alvarez-Lopeztello, Hernández-Cuevas, del Castillo, \& Robles (2019) menciona que los tipos de vegetación contigua en paisajes neotropicales pueden mostrar diferencias significativas en la composición de especies de HMA, densidad de esporas y colonización de raíces.

Respuesta de las plantas de café a la inoculación micorrízica: Existen reportes que indican que cuando las semillas de café se inoculan desde semillero, resisten el trasplante a vivero, donde permanecen menos tiempo del requerido y cuentan con mejor estado nutrimental, lo cual se refleja en el crecimiento y desarrollo de la planta, característica que permite su supervivencia en campo (Hernández-Acosta et al., 2018) y altos rendimientos Vallejos-Torres et al. (2019).

El beneficio de los HMA en plantas inoculadas dependerá de la cantidad de fertilizante fosfatado que se utilice y la frecuencia de aplicación, así como del contenido de fósforo en el suelo, una vez establecidas en campo. Otro factor para considerar es la diversidad de especies de HMA y patógenos nativos que existan en el suelo (Herrera-Monroy et al., 2019; Gómez \& Pulido, 2019). Un beneficio adicional del uso de HMA entre los cafeticultores, es en el establecimiento de fincas orgánicas, ya que el café certificado tiene mejor precio en el mercado. En México, el estado de Chiapas es el mayor productor de café en el país (SADER, 2019). La región del Soconusco utiliza activamente la inoculación micorrízica, desde la etapa de semillero hasta la cosecha. Como resultado los productores aprovechan mejor los nutrimentos del suelo, el agua; además de incrementar la capacidad fotosintética de sus plantaciones y de la biomasa carbonada (Adriano-Anaya, Jarquín-Gálvez, Hernández-Ramos, FigueroaMiguel, \& Monreal-Vargas, 2011).

En El Salvador, Moisés, Tamayo y Barraza (2015) inocularon café con Glomus cubense y Rhizophagus intraradices, obteniendo un incremento en distintas variables de crecimiento con respecto a plantas no inoculadas, lo que se tradujo en un ahorro de 719,10 dólares. La eficiencia de los HMA en el cultivo del café se incrementa cuando se inocula con bacterias promotoras del crecimiento. Adriano-Anaya et al. (2011) biofertilizaron con Rhizophagus 
intrarradices, Azospirillum sp. y Azotobacter sp. semillas de café para su producción orgánica en Chiapas, México y obtuvieron un incremento en las variables de crecimiento en un 30 $\%$, con respecto a las no inoculadas.

Beneficios nutrimentales en plantas de café, por efecto de la micorrización: El fósforo es un nutrimento que con frecuencia no se encuentra disponible en los suelos cafetaleros o existe en formas no disponible para las plantas, por esta razón, la aplicación de HMA favorece la absorción de fosfatos del suelo. Sin embargo, la simbiosis café-micorriza es más efectiva cuando el contenido de fósforo en el suelo no rebasa los $50 \mathrm{mg} \mathrm{kg}^{-1}$ (Siqueira \& ColozziFilho, 1986), ya que una mayor concentración inhibe el efecto de los HMA en las plantas de café (Barrer, 2009). Este cultivo se desarrolla en suelos tropicales ácidos que retienen fósforo, por eso se debe inocular antes del trasplante (Barrer, 2009).

En la producción de café es común el uso de compostas y vermicompostas, que junto con el uso de biofertilizantes a base de HMA, bacterias fijadoras de nitrógeno y solubilizadores de fósforo, promueven prácticas agronómicas amigables y compatibles con el medio ambiente (Hernández-Acosta et al., 2018; Perea-Rojas et al., 2019). Pruebas con Rhizophagus clarus en café, mostraron un aumento significativo en la biomasa (80\%), altura (45\%), contenido de fósforo (de 45.5 a $70.6 \%$ ), nitrógeno (del 52.3 a $197 \%$ ) y potasio $(26.7 \%)$ con respecto a las plantas no inoculadas (Fonseca et al., 2019).

Valverde-Lucio et al. (2020) estudiaron la eficiencia de HMA en la producción de café, encontrando un aumento en clorofila en plantas micorrizadas a 120 días después de la inoculación (ddi) y un nivel de nitrógeno en materia seca de $2.84 \%$ que representó un incremento de $98 \%$ comparado con las plantas testigo. Resultados similares observaron Adriano-Anaya et al. (2011), cuando inocularon Rhizophagus intraradices en plántulas de café para la producción orgánica en Chiapas, México; a los 112 ddi, sus resultados mostraron que el contenido de nitrógeno fue $85 \%$ mayor en las plantas inoculadas en comparación con las que no lo estuvieron. En agroecosistemas cafetaleros de México, Aguirre-Medina et al. (2011), reportaron que la cepa Rhizophagus irregularis, originó incrementos en el contenido de nitrógeno $(2.9 \%)$, fósforo $(0.19 \%)$ y calcio $(1.4 \%)$ a los 150 ddi, lo cual se manifestó en incrementos con respecto al testigo de $65 \%$ para nitrógeno, $74 \%$ (fósforo) y $40 \%$ (calcio).

La aplicación de HMA en café se realiza desde semilla para que al momento del trasplante a vivero y a campo reciban los beneficios nutrimentales que el hongo genera, y se reflejen en su desarrollo y crecimiento (Tabla 1).

\section{Los HMA y la supresión de enfermeda-} des en las plantas de café: Entre los factores que impactan negativamente el rendimiento agrícola de un cultivo, se encuentra la presencia de las enfermedades (Latorre, 2018; Vergara et al., 2019) y las plantaciones de café no son la excepción (Lagos-Burbano et al., 2019).

Distintos autores (Tabla 2) reportan los mecanismos de protección de los HMA al sistema radical: 1) al proporcionar una barrera física al patógeno que invade, 2) al competir con el patógeno por recursos y espacios vitales, 3) al producir una variedad de antibióticos y otras toxinas que actúan contra los organismos patogénicos (químicos antagónicos) y 4) al cambiar la cantidad y tipo de exudados radicales de la planta que deterioran a las poblaciones antagónicas de la micorrizósfera.

Cuando aumenta la capacidad y la habilidad de la planta para incorporar agua y nutrimentos, es posible que el estatus nutricional le permita tolerar el ataque por patógenos (Bertolini et al., 2018; Sánchez-Santillán, 2017). La asociación de los HMA con los cafetos evidencia que la simbiosis establecida contribuye a reducir los daños que algunos patógenos pudieran ocasionar a su sistema radical (Gaitán et al., 2011; Trejo-Aguilar, Ferrera-Cerrato, Sangabriel-Conde, \& Baeza (2018) o foliar (Perez-Vicente, 2014), por lo que la micorriza promueve la tolerancia de un hospedero a los patógenos (Osorio, 2012; Cisneros, Franco, Realpe-Fernández \& Fuenmayor, 2017). 
TABLA 1

Reportes del efecto de los hongos micorrizícos sobre el crecimiento de las plantas de café

TABLE 1

Reports of the effect of mycorrhizal fungi in coffee plant growth

\begin{tabular}{|c|c|c|c|}
\hline Consorcio o especie & Incremento $(\%)$ & Variable & Fuente \\
\hline $\begin{array}{l}\text { Consorcio a } 295 \text { días después del trasplante } \\
\text { (ddt), Acaulospora rugosa, Acaulospora foveata, } \\
\text { Acaulospora mellea, Glomus geosporum, Glomus } \\
\text { sinuosum, Glomus sp. 1, Glomus sp. y Ambispora } \\
\text { appendicula }\end{array}$ & 80 & Altura & Vallejos-Torres et al. (2019) \\
\hline R. intraradices a $117 \mathrm{dds}$ & 86 & & Moisés et al. (2015) \\
\hline R. intraradices a 140 dds & 87 & & $\begin{array}{l}\text { Ibarra-Puón, Aguirre-Medina, } \\
\text { Ley-De Coss, Cadena-Iñiguez, } \\
\text { \& Zavala-Mata (2014) }\end{array}$ \\
\hline Glomus clarum y Gigaspora margarita a 150 (ddi) & 37 & Área foliar & França et al. (2014) \\
\hline R. intraradices a $117 \mathrm{dds}$ & 65 & & Moisés et al. (2015) \\
\hline $\begin{array}{l}\text { Consorcio (Glomus claroides, Rhizophagus } \\
\text { diaphanus y Paraglomus albidum) a } 335 \mathrm{dds}\end{array}$ & 910 & $\begin{array}{l}\text { Volumen } \\
\text { de la raíz }\end{array}$ & Hernández-Acosta et al. (2018) \\
\hline R. intraradices a $117 \mathrm{dds}$ & 74 & Materia seca & Aguirre-Medina et al. (2011) \\
\hline Rhizophagus irregularis a $140 \mathrm{dds}$ & 52 & & Ibarra-Puón et al. (2014) \\
\hline
\end{tabular}

El aumento en el desarrollo de las plantas de café provocado por la presencia del hongo micorrízico, en parte está relacionado al efecto nutrimental dado por el biofertilizante; esto origina en la planta tolerancia al ataque de plagas por nemátodos (Meloidogyne sp.) y enfermedades como la roya (Hemileia vastatrix). Otro efecto de la simbiosis establecida con los HMA es que incrementa el contenido de fitohormonas, flavonoides e isoflavonoides (Salloum et al., 2019) que intervienen en las funciones vitales y vigor vegetal (Kiers, West, \& Denison, 2002).

El principal patógeno que ataca a las plantas de café es Hemilleia vaxtratix y la estrategia para combatirlo, se ha centrado en la resistencia con nuevas variedades de café. Estas nuevas variedades, pudieran volverse resistentes, no solo al hongo patógeno, sino también al HMA (Salloum et al., 2019). Este fenómeno se ha observado en variedades nuevas que ya no están respondiendo a la inoculación o que tienen bajos porcentajes de colonización (Hernández-Acosta et al., 2018). Se considera que los trabajos de mejoramiento del café deben realizarse de la mano con la respuesta a la micorrización.

La práctica de la micorrización en plantas de café permite que éstas crezcan sanas, vigorosas y generen rendimientos altos. El cultivo de café es dependiente de la micorriza arbuscular para su nutrición, incrementa en la planta el contenido de fósforo, nitrógeno y calcio en suelos ácidos y poco fértiles. 
TABLA 2

Efectos reportados sobre la interacción plantas de café inoculadas con HMA vs patógeno-parásitos

TABLE 2

Reported effects about the interaction of coffee plants inoculated with arbuscular mycorrhizal fungi vs pathogen-parasites

\begin{tabular}{|c|c|c|}
\hline $\begin{array}{l}\text { HMA y/o género y especie(s) de } \\
\text { micobionte referido(s) }\end{array}$ & Efecto(s) observado(s) & Fuente \\
\hline Gigaspora margarita & $\begin{array}{l}\text { Más la adición de fósforo }(\mathrm{P}) \text { disminuye daños provocados } \\
\text { por Meloidogyne incognita. }\end{array}$ & $\begin{array}{l}\text { Lopes, Portugal, Gonçalves, } \\
\text { Dias, \& Costa (1987) }\end{array}$ \\
\hline Consorcio de HMA & Reducción de daños por Pratylenchus coffeae. & $\begin{array}{l}\text { Baon, Wiryadiputra, \& } \\
\text { Sulistyowati, (1988) }\end{array}$ \\
\hline Gigaspora margarita & $\begin{array}{l}\text { Más adición de } \mathrm{P}\left(200 \mathrm{mg} \mathrm{kg}^{-1}\right) \text {, atenuaron daños por } \\
\text { Meloidogyne exigua. }\end{array}$ & $\begin{array}{l}\text { Lana, Zambolin, do Valle, \& } \\
\text { dos Santos (1991) }\end{array}$ \\
\hline Gigaspora margarita & $\begin{array}{l}\text { La aplicación de } \mathrm{P} \text { generó la tolerancia a la presencia de } \\
\text { Rhizoctonia solani ( }>4 \text { veces). }\end{array}$ & Pereira (1994) \\
\hline Consorcio de HMA (MTZ-1) & $\begin{array}{l}\text { Más adición de P (1 } 600 \text { ppm kg-1), presentaron menor } \\
\text { índice de severidad de Phoma costarricencis. }\end{array}$ & Escalona (2002) \\
\hline $\begin{array}{l}\text { Aislamiento nativo de } \\
\text { Entrophospora } \mathrm{sp} .\end{array}$ & $\begin{array}{l}\text { Disminución del daño foliar de Colletotrichum } \\
\text { gloesporoides, reportando } 11.2 \% \text { de daño en plantas } \\
\text { micorrizadas contrastando con } 47.72 \% \text { del testigo. }\end{array}$ & Colmenárez \& Pineda (2006) \\
\hline Especies nativas $\mathrm{n} / \mathrm{r}$ & $\begin{array}{l}\text { Disminución de agallas causadas por Meloidogyne exigua } \\
\text { ( } 76.4 \text { agallas NM vs } 25.2 \mathrm{M} \text { previo a la infección de } \\
\text { nemátodos). }\end{array}$ & $\begin{array}{l}\text { Alban, Guerrero, \& Toro } \\
\text { (2013) }\end{array}$ \\
\hline \multirow[t]{2}{*}{$\begin{array}{l}\text { Claroideoglomus etunicatum y } \\
\text { Entiscutata heterogama }\end{array}$} & $\begin{array}{l}\text { Reduce el efecto nocivo de la maleza, hubo un aumento } \\
\text { en la altura }(12 \%) \text {, el área foliar }(24 \%) \text { y la masa seca } \\
\text { de la raíz }(21 \%) \text { y un incremento en el número de ramas } \\
\text { plagiotrópicas de } 16 \% \text { con Claroideoglomus etunicatum. }\end{array}$ & França et al. (2016) \\
\hline & $\begin{array}{l}\text { Disminución de la severidad por daño de Cercospora } \\
\text { coffeicola porcentajes de } 10.3 \% \text { de severidad vs } 100 \% \text { en } \\
\text { el testigo. }\end{array}$ & Guzmán \& Rivillas (2007) \\
\hline $\begin{array}{l}\text { Mezcla de especies nativas } \\
\text { (14 especies identificadas) }\end{array}$ & $\begin{array}{l}\text { Efecto positivo en el tamaño de las plantas infectadas por } \\
\text { Fusarium solani, incrementaron } 14 \mathrm{~cm} \text { el tamaño de la } \\
\text { planta. }\end{array}$ & Al-Areqi et al. (2015) \\
\hline
\end{tabular}

Declaración de ética: los autores declaran que todos están de acuerdo con esta publicación y que han hecho aportes que justifican su autoría; que no hay conflicto de interés de ningún tipo; y que han cumplido con todos los requisitos y procedimientos éticos y legales pertinentes. Todas las fuentes de financiamiento se detallan plena y claramente en la sección de agradecimientos. El respectivo documento legal firmado se encuentra en los archivos de la revista.

\section{RESUMEN}

Introducción: El café es una planta altamente micotrófica, por lo que la interacción con los hongos micorrízicos arbusculares (HMA) se ha estudiado en distintos países tropicales. La mayoría de los trabajos publicados indican que el café se beneficia de la asociación micorrízica, donde los HMA confieren protección ante patógenos y enfermedades, incrementa la absorción de agua, así como la adaptación de la planta durante el trasplante de vivero al campo. Objetivo: Se realizó una revisión donde se resumieron y analizaron trabajos reportados por la asociación de HMA y café de los últimos 10 años, enfocada en la distribución 
global de especies de HMA, beneficio nutricional de la asociación y su interacción con patógenos. Métodos: Se revisaron diferentes bases de datos que reportaron trabajos realizados en los principales países productores de café. La revisión se centró principalmente en los trabajos publicados entre el 2000 y el 2019, sin embargo, en algunos casos se incluyeron artículos clásicos en el tema, que no corresponden al periodo señalado, principalmente los realizados en Brasil desde 1986. Se organizó el número de especies reportadas por país, se buscaron sinonimias y agruparon por familia, género y especie. Los trabajos donde solo se reportan géneros o las especies presentaron ambigüedad, se usaron como referencia, pero no se incluyeron en el análisis final. Se resumieron los reportes de los beneficios de la interacción de HMA con café, así como la tolerancia a patógenos. Resultados: Los datos recabados muestran que hay más de 100 especies de HMA asociadas con el café, lo cual representa más de la tercera parte del total de las especies reportadas en el mundo. En Colombia se reportó la mayor riqueza de especies de HMA, lo cual puede deberse a que es el país con más reportes en el tema. Conclusiones: Esta información muestra los beneficios de la incorporación de HMA en los programas de replantación de fincas de café, pues estos hongos son un elemento clave en la nutrición de los cafetos, sin embargo, se debe considerar la variedad de café cultivada y la introducción de HMA, pues no en todas hay una asociación exitosa.

Palabras clave: biodiversidad; café; especie generalista; rizosfera; simbiosis.

\section{REFERENCIAS}

Adriano-Anaya, M.L., Jarquín-Gálvez, J., HernándezRamos, C., Figueroa-Miguel, S., \& Monreal-Vargas, C.T. (2011). Biofertilización de café orgánico en etapa de vivero en Chiapas, México. Revista Mexicana de Ciencias Agrícolas, 2(1), 417-431.

Aguirre-Medina, J.F., Moroyoqui-Ovilla, D.M., MendozaLópez, A., Cadena-Iñiguez, J., Avendaño-Arrazate, C.H., \& Aguirre-Cadena, J.F. (2011). Hongo endomicorrízico y bacteria fijadora de nitrógeno inoculadas a Coffea arabica en vivero. Agronomía Mesoamericana, 22(1), 71-80.

Al-Areqi, A.H., Chliyeh, M., Touati, J., Ali, O., Sghir, F., Touhami, A.O., Benkirane, R., \& Douira, A. (2015). Effect of endomycorrhizae on decline of the coffee plants (Coffea arabica) caused by Fusarium solani. International Journal of Advances in Pharmacy, Biology, and Chemistry, 4(2), 397-404.

Alban, R., Guerrero, R., \& Toro, M. (2013). Interactions between a root-knot nematode (Meloidogyne exigua) and arbuscular mycorrhizae in coffee plant development (Coffea arabica). American Journal of Plant Sciences, 4, 19-23.
Alvarez-Lopeztello, J., Hernández-Cuevas, L.V., del Castillo, R.F., \& Robles, C. (2019). Diversity of arbuscular mycorrhizal fungi associated with Brachiaria brizantha pastures in lowlands of Oaxaca, Mexico. Grassland Science, 65, 1-5.

Arévalo, Y. (2018). Evaluación y Caracterización de Hongos Micorrizicos Arbusculares en Tres Agroecosistemas y Dos Bosques en las Provincias de Alto Amazonas y Lamas (Tesis de grado). Universidad Nacional Agraria La Molina, Lima, Perú.

Arias, R.M., Heredia-Abarca, G., Sosa, V.J., \& FuentesRamírez, L.E. (2012). Diversity and abundance of arbuscular mycorrhizal fungi spores under different coffee production systems and in a tropical montane cloud forest patch in Veracruz, Mexico. Agroforestry Systems, 85, 179-193.

Arif, S., Yusnaini, S., Niswati, A., Setiawan, A., Tuchida, K., Katou, T., ... Nonaka, M. (1999). Population of arbuscular mycorrhizal fungi (AMF) by different land use in Sumatra, Indonesia. Microbes and Environments, 14(1), 9-17.

Baon, J.B., Wiryadiputra, S., \& Sulistyowati, E. (1988). Pengaruh infeksi mikoriza terhadap serangan nematoda Platylenchus coffeae pada tanaman kopi. Pelika Perkebunan, 4(1), 22-30.

Barrer, S.E. (2009). El uso de hongos micorrízicos arbusculares como una alternativa para la agricultura. Facultad de Ciencias Agropecuarias, 7(1), 1-10.

Bertolini, V., Montaño, N.M., Chimal, E., Varela, L., Gómez, J., \& Martínez, J.M. (2018). Abundancia y riqueza de hongos micorrizógenos arbusculares en cafetales de Soconusco, Chiapas, México. Revista de Biología Tropical, 66(1), 91-105.

Bertolini, V., Montaño, N.M., Salazar, B.L., Chimal, E., \& Varela, L. (2020). Diversidad de hongos micorrizógenos arbusculares en plantaciones de café (Coffea arabica) del volcán Tacaná, Chiapas, México. Acta Botánica Mexicana, 127, e1602.

Bhattacharya, S., \& Bagyraj, D. (2002). Arbuscular mycorrhizal fungi associated with Coffee arabica. Geobios, 29(1), 93-96.

Bodstock, M., Rodden, K., \& Russell, K. (2017). Sunburst (version 0.6.5. "R package"). Retrieved from https:// CRAN.R-project.org/package $=$ sunburstR

Camargo-Ricalde, S.L., Montaño-Arias, N.M., De la RosaMera, C.J., \& Montaño-Arias, S.A. (2012). Micorrizas: una gran unión debajo del suelo. Revista Digital Universitaria, 13(7), 1-19.

Campanha, M.M., Santos, R.H.S., De Freitas, G.B., Martinez, H.E.P., Garcia, S.L.R., \& Finger, F.L. (2004). Growth and yield of coffee plants in agroforestry and monoculture systems in Minas Gerais, Brazil. Agroforestry Systems, 63(1), 75-82. 
Cardona-Calle, D.A., \& Sadeghian-Kh, S. (2005). Aporte de material orgánico y nutrientes en cafetales al sol y bajo sombrío de guamo. Avances Técnicos Cenicafé, $334,1-8$.

Cardoso, L., Alves da Silva, D.K., Costa, I.E., da Silva, J.M., de Moura, I.A., \& Oehl, F. (2020). Changes in an arbuscular mycorrhizal fungi community along and environmental gradient. Plants, 9(1), 52-68.

Chen, H. (2018). VennDiagram (version 1.6.2, "R package") Retrieved from https://cran.r-project.org/web/ packages/VennDiagram/index.html

Cisneros, C.A., Franco, J.M., Realpe-Fernández, M., \& Fuenmayor, J.C. (2017). Influencia de microorganismos en la disponibilidad de fósforo en plántulas de café (Coffea arabica). Biotecnología en el Sector Agropecuario y Agroindustrial, 15(1), 19-26.

Cogo, F.D., Guimarães, P.T.G., Rojas, E.P., Saggin, O.J., Siqueira, J.O., \& Carneiro, M.A.C. (2017). Arbuscular mycorrhiza in Coffea arabica L.: review and meta-analyses. Coffee Science, 12(3), 15.

Colmenárez-Betancourt, F.A., \& Pineda, J.B. (2006). Relación entre micorrizas en cafeto y la antracnosis por Colletotrichum gloeosporioides Penz. VII Congreso SEAE Zaragoza, 179, 1-9.

Colozzi-Filho, A., \& Nogeira-Cardoso, E.J.B. (2000). Detection of arbuscular mycorrhizal fungi in roots of coffee and crotalaria cultivated between rows. Pesquisa Agropecuaria Brasileira, 35(10), 2033-2042.

De Beenhouwer, M., Van Geel, M., Ceulemans, T., Muleta, D., Lievens, B., \& Honnay, O. (2015). Changing soil characteristics alter the arbuscular mycorrhizal fungi communities of Arabica coffee (Coffea arabica) in Ethiopia across a management intensity gradient. Soil Biology and Biochemistry, 91(1), 133-139.

De Carvalho, F., De Souza, F.A., Carrenho, R., de Souza Moreira, F.M., Da Conçeição Jesus, E., \& Fernandes, G.W. (2012). The mosaic of habitats in the highaltitude Brazilian rupestrian fields is a hotspot for arbuscular mycorrhizal fungi. Applied Soil Ecology, 52(1), 9-19.

Escalona, M.A. (2002). Interacción de plantas de café fertilizadas con fósforo e inoculadas con hongos micorrizico arbusculares y Phoma costarricencis Echandi (Tesis de Maestría). Universidad de Colima, México.

Pérez-Vicente, L. (16-18 de septiembre 2014). La roya del cafeto (Hemileia vastatrix) en Cuba: Evolución al manejo alternativo de la enfermedad. En Memorias del Seminario Científico Internacional Manejo Agroecológico de la Roya del Café. Ciudad de Panamá, Panamá.

Farreras, P.J.A. (2018). El café bajo sombra como sistema agroforestal. Revista Equidad, 2, 23-30.
Fernández, R., De Guglielmo, Z., \& Menéndez, A. (2010). Cultivo de tejidos y transformación genética del café. Revista de Investigación, 34(71), 57-84.

Fester, T. (2013). Arbuscular mycorrhizal fungi in a wetland constructed for benzene-, methyl tert-butyl ether-and ammonia-contaminated groundwater bioremediation. Microbial Biotechnology, 6(1), 80-84.

Filho-Virginio, E.D.M., Casanoves, F., Haggar, J., Staver, C., Soto, G., Avelino, J., ... Vasquez, A. (2015). La productividad útil, la materia orgánica y el suelo en los primeros 10 años de edad en sistemas de producción de café a pleno sol y bajo varios tipos de sombra $\mathrm{y}$ niveles de insumos orgánicos y convencionales en Costa Rica. In F. Montagnini, E. Somarriba, E. Murgueitio, H. Fassola, \& B. Eibl (Eds.), Sistemas Agroforestales. Funciones Productivas, Socioeconómicas y Ambientales (pp. 131-151). Turrialba, Costa Rica: Informe técnico CATIE.

Fonseca, A., de Freitas, A.F., Rodrigues-Carvalho, G., Carbone-Carneiro, M.A., Martinis, D.J., \& de Oliveira, L. (2019). Arbuscular mycorrhizal fungus on the initial growth and nutrition of Coffea arabica L. genotypes. Ciência e Agrotecnologia, 43, e006919.

França, A., de Freitas, A.F., dos Santos, E., Grazziotti, P.H., \& Andrade, V.C.D. (2016). Mycorrhizal fungi increase coffee plants competitiveness against Bidens pilosa interference. Pesquisa Agropecuaria Tropical, 46(2), 132-139.

França, A.C., Carvalho, F.P., Franco, M.H.R., de Avelar, M., Souza, B.P., \& Stürmer, S.L. (2014). Crescimento de mudas de cafeeiro inoculadas com fungos micorrízicos arbusculares. Revista Brasileira de Ciêncas Agrárias, 9(4), 506-511.

Gaitán, A.L., Villegas, G.C., Rivillas, O.C.A., Hincapié, G.E., \& Arcilla, P.J. (2011). Almácigos de café: Calidad fitosanitaria, manejo y siembra en el campo: Avances Técnicos. Caldas, Colombia: Cenicafé, Programa de Investigación Científica, Fondo Nacional del Café.

García-Alvarado, M.E., Díaz-Zorrilla, G.O., CastañedaHidalgo, E., Lozano-Trejo, S., \& Pérez-León, M.I. (2017). Caracterización del agroecosistema de café bajo sombra en la cuenca del río copalita. Revista Mexicana de Agronegocios, 40, 635-648.

Garza-Lau, R., Maldonado-Torres, R., Álvarez-Sánchez, M.E., \& Torres-Rivera, J.A. (2020). Caracterización de especies arbóreas asociadas al cultivo de café. Revista Mexicana de Ciencias Agrícolas, 11(1), 25-3.

Gómez, D., \& Pulido, L. (2019). Hongos micorrízicos arbusculares y trichoderma harzianum r: alternativas ecológicas para la producción de posturas de café (Coffea arabica L.) en el estado Táchira, Venezuela. Universidad \& Ciencia, 8, 12-28. 
Guzmán, O.A., \& Rivillas, C.A. (2007). Relación de Glomus manihotis y $G$ fasciculatum con el crecimiento de plantas de café y la severidad de la mancha de hierro. Cenicafé, 58(3), 236-257.

Hernández-Acosta, E., Trejo-Aguilar, D., Rivera-Fernández, A., \& Ferrera-Cerrato, R. (2020). La micorriza arbuscular como biofertilizante en cultivo de café. Terra Latinoamericana, 38-3, 613-628. DOI: 10.28940/terra.v38i3.659

Hernández-Acosta, E., Ferrera-Cerrato, R., \& Trejo-Aguilar, D. (1996). Dinámica de la colonización de la endomicorriza en café en fase de semillero. En J. Pérez-Moreno, \& R. Ferrera-Cerrato (Eds.), Nuevos horizontes de la Agricultura en México, Agroecología y Desarrollo Sostenible (pp. 77-79). Monteci1los, México: Colegio de Postgraduados en Ciencias Agrícolas.

Hernández-Acosta, E., Trejo-Aguilar, D., Ferrera-Cerrato, F., Rivera-Fernández, A., \& González-Chávez, M.C. (2018). Hongos micorrízicos arbusculares en el crecimiento de café (Coffea arabica L.) variedades garnica, catimor, caturra y catuaí. Agroproductividad, 11(4), 61-67.

Herrera-Monroy, S., Castro-Brindis, R., Pérez-Moreno, J., \& Valdés-Velarde, E. (2019). Endomycorrhizal diversity in coffee plants (Coffea arabica L.) infected with rust (Hemileia vastatrix). Nova Scientia, 11(22), 102-123.

Ibarra-Puón, J.C., Aguirre-Medina, J.F., Ley-De Coss, A., Cadena-Iñiguez, J., \& Zavala-Mata, G.A. (2014). Coffea canephora (Pierre) ex Froehner inoculado con micorriza y bacteria fijadora de nitrógeno en vivero. Revista Chapingo Serie Horticultura, 20(2), 201-213.

Jaramillo, R. (2011). La micorriza arbuscular (MA) centro de la rizósfera: comunidad microbiológica dinámica del suelo. Revista Contactos, 81, 17-23.

Jefwa, J., Mungatu, J., Okoth, P., Muya, E., Roimen, H., \& Njuguini, S. (2009). Influence of land use types on occurrence of arbuscular mycorrhizal fungi in the high-altitude regions of Mt. Kenya. Tropical and Subtropical Agroecosystems, 11(2), 277-290.

Julca-Otiniano, A., Alarcón-Águila, G., Alvarado-Huamán, L., Borjas-Ventura, R., \& Castro-Cepero, V. (2018). Comportamiento de tres cultivares de café (catimor, colombia y costa rica 95) en el valle del perené, junín, Perú. Chilean Journal of Agricultural \& Animal Sciences, 34(3), 205-215.

Kiers, E.T., West, S.A., \& Denison, R.F. (2002). Mediating mutualisms: Farm management practices and evolutionary changes in symbiont co-operation. Journal of Applied Ecology, 39(5), 745-754.

Kivlin, S.N., Hawkes, C.V., \& Treseder, K.K. (2011). Global diversity and distribution of arbuscular mycorrhizal. Soil Biochemistry, 43(11), 2294-2303.
Lagos-Burbano, T.C., Criollo-Escobar, H., García-Álzate, J., Muñoz-Belalcazar, J., López Gómez, J., Benavides-Arteaga, V., \& Dulce-Delgado, J. (2019). El cultivo del Café (Coffea arabica L.) en Nariño: cartilla divulgativa. San Juan de Pasto, Colombia: Editorial Universidad de Nariño.

Lana, M.M., Zambolin, L., do Valle, F.X.R., \& dos Santos, J.M. (1991). Tolerãncia do cafeeiro (Coffea arabica) ao nematóide Meloidogyne exigua induzida por fungos micorrízicos. Fitopatologia Brasileira, 16(1), $50-54$.

Latorre, G.B. (2018). Compendio de las enfermedades de las plantas. Santiago de Chile, Chile: Ediciones UC.

Lebrón, L., Lodge, D.J., \& Bayman, P. (2012) Differences in arbuscular mycorrhizal fungi among three coffee cultivars in Puerto Rico. International Scholarly Research Notices, 1-7. DOI: 10.5402/2012/148042

Lopes, E.S., Portugal, E.P., Gonçalves, W., Dias, R., \& Costa, W.M. (1987). Interações entre micorrizas, adubações fosfatadas e Meloidogyne incognita em mudas de cafeeiro (Coffea arabica cv. Mundo Novo). In Programas e resumos de Reunião Brasileira sobre Micorrizas, 2 (pp. 33-34). São Paulo, Brazil: Secretaria do Meio Ambiente e da Agricultura.

Lu, N., Xu, X., Wang, P., Zhang, P., Ji, B., \& Wang, X. (2019). Succession in arbuscular mycorrhizal fungi can be attributed to a chronosequence of Cunninghamia lanceolata. Scientific Reports, 9(1), 1-12.

Mahdhi, M., Tounekti, T., Al-Turki, T.A., \& Khemira, H. (2017). Composition of the root mycorrhizal community associated with Coffea arabica in Fifa Mountains (Jazan region, Saudi Arabia). Journal of Basic Microbiology, 57(8), 691-698.

Maia, L.C., Passos, J.H., Silva, J.A., Oehl, F., \& Assis, D.M.A. (2020). Species diversity of Glomeromycota in Brazilian biomes. Sydowia, 72, 181-205.

Manson, R.H., Hernández-Ortíz, V., Gallina, S., \& Mehltreter, K. (2008). Agroecosistemas cafetaleros de Veracruz biodiversidad manejo y conservación. México, D.F., México: Instituto Nacional de Ecología INE-SEMARNAT.

Meena, R.S., Kumar, S., Datta, R., Lal, R., Vijayakumar, V., Brtnicky, M., \& Pathan, S.I. (2020). Impact of agrochemicals on soil microbiota and management: A review. Land, 9(2), 34.

Méndez, V.E., Bacon, C.M., Olson, M.B., Morris, K.S., \& Shattuck, A. (2013). Conservación de agrobiodiversidad y medios de vida en cooperativas de café bajo sombra en Centroamérica. Ecosistemas, 22(1), 16-24.

Moguel, P., \& Toledo, V.M. (1999). Biodiversity Conservation in Traditional Coffee Systems of Mexico. Conservation Biology, 13, 11-21. 
Moisés, L.G., Tamayo, Y., \& Barraza, F.V. (2015). Alternativa ecológica y económica para la obtención de postura de Coffea arabica L. Revista de Ciencias Agrícolas, 32(1), 65-74.

Moreira, S.D., França, A.C., Grazziotti, P.H., Leal, F.D.S., \& Silva, E.D.B. (2019). Arbuscular mycorrhizal fungi and phosphorus doses on coffee growth under a nonsterile soil. Revista Caatinga, 32(1), 72-80.

Noriega-Altamirano, G., Cárcamo-Rico, B., Gómez-Cruz, M.A., Schwentesius-Rindermann, R., Cruz-Hernández, S., Leyva-Baeza, J., ... Martínez-Hernández, A. (2014). Intensificación de la producción en la agricultura orgánica: caso café. Revista Mexicana de Ciencias Agrícolas, 5(1), 163-169.

Oehl, F., Laczko, E., Bogenrieder, A., Stahr, K., Bösch, R., van der heiden, M., \& Sievering, E. (2010). Soil type and land use intensity determine the composition of arbuscular mycorrhizal fungal communities. Soil Biology and Biochemistry, 24(5),724-738.

Ontivero, R.E., Voyron, S., Allione, L.V.R., Bianco, P., Bianciotto, V., Iriarte, H.J., ... Lumini, E. (2020). Impact of land use history on the arbuscular mycorrhizal fungal diversity in arid soils of Argentinean farming fields. FEMS Microbiology Letters, 367(14), 114.

Ortaş, İ. (2020). Mycorrhizas in fruit nutrition: Important breakthroughs. In A.K. Srivastava \& C. Hu (Eds.), Fruit Crops Diagnosis and Management of Nutrient Constraints (pp. 339-351). Ámsterdam, Netherlaands: Elsevier.

Ortiz-Acevedo, A., Osorio-Vega, N.W., Echeverri-Gómez, J., González-Murillo, O.A.Ç., \& Medina-Sierra, M. (2015). Fisiología de los hongos formadores de micorrizas arbusculares. Livestock Research for Rural Development, 27, Article \#188. Recuperado de http:// www.lrrd.org/lrrd27/9/orti27188.html.

Osorio, N.W. (2012). Uso de hongos formadores de micorriza como alternativa biotecnológica para promover la nutrición y el crecimiento de plántulas. Recuperado de http://www.walterosorio.net, Universidad Nacional de Colombia-Sede Medellín.

Parra, M., Sánchez, M., \& Sieverding, E. (1990). Efecto de micorriza vesiculo-arbuscular en café Coffea arabica L. variedad Colombia en almacigo. Acta Agronómica, 40(1-2), 88-99.

Perea-Rojas, Y., Arias, R.M., Medel-Ortiz, R., Trejo-Aguilar, D., Heredia, G., \& Rodríguez, Y. (2019). Effects of native arbuscular mycorrhizal and phosphate-solubilizing fungi on coffee plants, Agroforestry Systems, 93, 961-972.

Pereira, L.A.A. (1994). Desenvolvimento de mudas de cafeeiro (Coffea arabica L.) na presença de Gigaspora margarita Becker e Hall e Rhizoctonia solani
Kuhn (Dissertação de Maestrado). Escola Superior de Agricultura de Lavras, Minas Gerais, Brazil.

Pérez-Lavalle, L., Bolívar-Anillo, H.J., \& Díaz-Pérez, A. (2017). Biofertilizantes en Colombia. In H.H. Estrada-López, H.G. Saumett-España, M.A. IglesiasNavas, M.J. Bahamón, A.M. Cáceres-Martelo, C.E. Restrepo-Flórez, \& A. Díaz-Pérez (Eds.), Productos de confitería nutracéutica. Una opción empresarial para cultivadores de frutas y hortalizas (pp. 179222). Barranquilla, Colombia: Universidad Simón Bolívar.

Pérez-Luna, Y., Alvarez-Solís, D., Hernández-Cuevas, L., \& Sánchez-Roque, Y. (2016). Acaulospora excavata (Glomeromycota) in agricultural soils of Chiapas, México. Interantional Journal of Advance Agricultural Research, 4, 6-9.

Peroza, C.V., \& Perez, C.A. (2010). Efecto de parámetros físicos, químico y salinidad sobre la densidad poblacional y la colonización de micorrizas arbusculares en pasto angleton en el municipio de Tolu, sucre, Colombia. Revista Colombiana de Ciencia Animal, 2(2), 310-324.

Posada, R.H., Heredia-Abarca, G., Sieverding, E., \& Sánchez, M. (2012) Solubilization of iron and calcium phosphates by soil fungi isolated from coffee plantations. Archives of Agronomy and Soil Science, 59, 185-196.

Posada, R.H., Sánchez, M., Heredia-Abarca, G., \& Sieverding, E. (2018). Effects of soil physical and chemical parameters, and farm management practices on arbuscular mycorrhizal fungi communities and diversities in coffee plantations in Colombia and Mexico. Agroforestry Systems, 92(2), 555-574.

Prates-Júnior, P., Moreira, B.C., da Silva, M.D.C.S., Veloso, T.G.R., Stürmer, S.L., Fernandes, R.B.A., \& Kasuya, M.C.M. (2019). Agroecological coffee management increases arbuscular mycorrhizal fungi diversity. PloS One, 14(1), e0209093.

Rajeshkumar, P.P., Thomas, G.V., Gupta, A., \& Gopal, M. (2015). Diversity, richness and degree of colonization of arbuscular mycorrhizal fungi in coconut cultivated along with intercrops in high productive zone of Kerala, India. Symbiosis, 65(3), 125-14.

Redecker, D., Schüßler, A., Stockinger, H., Stürmer, S.L., Morton, J.B., \& Walker, C. (2013). An evidencebased consensus for the classification of arbuscular mycorrhizal fungi (Glomeromycota). Mycorrhiza, 23, 515-531. DOI: 10.1007/s00572-013-0486-y

Reid, M.L., \& Emery, S.M. (2017). Native and exotic foundation grasses differ in traits and responses to belowground tri-trophic interactions. Plant Ecology, 218(2), 173-183.

Ritchie, M.E., Phipson, B., Wu, D., Hu, Y., Law, C.W., Shi, W., \& Smyth, G.K. (2015). Limma powers 
differential expression analyses for RNA-sequencing and microarray studies. Nucleic Acids Research, 43(7), 47. DOI: $10.1093 / \mathrm{nar} / \mathrm{gkv} 007$

Roskoski, J.P. (1982). Nitrogen fixation in a Mexican coffee plantation. In G.P. Robertson, R. Herrera, \& T. Rosswall (Eds.), Nitrogen Cycling in Ecosystems of Latin America and the Caribbean (pp. 283-291). Dordrecht, Netherlands: Springer.

Ruelas-Monjardín, L.C., Nava-Tablada, M.E., Cervantes, J., \& Barradas, V.L. (2014). Importancia ambiental de los agroecosistemas cafetaleros bajo sombra en la zona central montañosa del estado de Veracruz, México. Madera y Bosques, 20(3), 27-40.

Saggin-Júnior, O.J., \& Siqueira, J.O. (1996). Micorrizas arbusculares em cafeeiro. In J.O. Siqueira (Ed.), Avanços em fundamentos e aplicação de micorrizas (pp. 203-254). Minas Gerais, Brazil: UFLA.

Salloum, M.S., Insani, M., Monteoliva, M.I., Menduni, M.F., Silvente, S., Carrari, F., \& Luna, C. (2019). Metabolic responses to arbuscular mycorrhizal fungi are shifted in roots of contrasting soybean genotypes. Mycorrhiza, 29(5), 459-473.

Sánchez, C., Espinosa, R., Gonzalez, C., Cupull, R., Herrera, R., \& Varela, M. (2000). Efecto de la inoculación de hongos micorrizógenos (HMA) sobre la producción de posturas de cafetos en tres tipos de suelos del macizo montañoso Guamuhaya. Cultivos Tropicales, 21(3), 5-13.

Sánchez-Santillán, T. (2017). Efecto de inóculos de Hongos Micorrizicos Arbusculares en plantas clonales de café (Coffea arabica L.) variedad caturra en condiciones de invernadero, Rodríguez de Mendoza, Amazonas (Tesis de grado). Universidad Nacional Toribio Rodríguez de Mendoza de Amazonas, Chachapoyas, Perú.

SADER (Secretaría de Agricultura y Desarrollo Rural). (2019). Comunicado Bienestar para el Campo incorpora a cafetaleros. Recuperado de https://www. gob.mx/agricultura/prensa/bienestar-para-el-campoincorpora-a-cafetaleros-201155

Siqueira, J.O., \& Colozzi-Filho, A. (1986). Micorrizas vesículo-arbusculares em mudas de cafeeiro.II. Efeito do fósforo no establecimiento e funcionamento da simbiose. Sociedade Brasileira de Ciência do Solo, 10(3), 207-211.

Solís-Rodríguez, U.R.J., Ramos-Zapata, J.A., HernándezCuevas, L., Salinas-Peba, L., \& Guadarrama, P. (2020). Arbuscular mycorrhizal fungi diversity and distribution in tropical low flooding forest in Mexico. Mycological Progress, 19(3), 195-204.
Stevens, B.M., Propster, J.R., Öpik, M., Wilson, G.W., Alloway, S.L., Mayemba, E., \& Johnson, N.C. (2020). Arbuscular mycorrhizal fungi in roots and soil respond differently to biotic and abiotic factors in the Serengeti. Mycorrhiza, 30(1), 79-95.

Stürmer, S., Bever, J.D., \& Morton, J.M. (2018). Biogeography of arbuscular mycorrhizal fungi (Glomeromycota): a phylogenetic perspective on species distribution patterns. Mycorrhiza, 38, 587-603.

Stürmer, S.L., \& Siqueira, J.O. (2006). Chapter 10. Diversity of arbuscular mycorrhizal fungi in brazilian ecosystems. In F.M.S. Moreira, J.O. Siqueira, \& L. Brussaard (Eds.), Soil biodiversity in Amazonian and other Brazilian ecosystems (pp. 206-236). London, UK: CABI Publishing.

Trejo-Aguilar, D., Barois, I., \& Sangabriel-Conde, W. (2016). Disturbance and land use effect on functional diversity of the arbuscular mycorrhizal fungi. Agroforestry Systems, 90(2), 265-279.

Trejo-Aguilar, D., Ferrera-Cerrato, R., García, R., Varela, L., Lara, L., \& Alarcón, A. (2011). Efectividad de siete consorcios nativos de hongos micorrízicos arbusculares en plantas de café en condiciones de invernadero y campo. Revista Chilena de Historia Natural, 84(1), 23-31.

Trejo-Aguilar, D., Ferrera-Cerrato, R., Sangabriel-Conde, W., \& Baeza, Y. (2018). Efecto de la micorriza arbuscular en plantas de café (Coffea arabica L.) Infectadas por el nematodo de la corchosis de la raíz. Agroproductividad, 11(4), 98-104.

Tristão, F.S.M., Andrade, S.A.L.D., \& Silveira, A.P.D.D. (2006). Fungos micorrízicos arbusculares na formação de mudas de cafeeiro, em substratos orgânicos comerciais. Bragantia, 65(4), 649-658.

Vallejos-Torres, G., Arévalo, L., Iliquin, I., \& Solís, R. (2019). Field response of Coffee Clones to Inoculation with Consortium of Arbuscular Mycorrhizal Fungi in the Amazonas Region, Peru. Información Tecnológica, 30(6), 73-84.

Valverde-Lucio, Y., Moreno-Quinto, J., Quijije-Quiroz, K., Castro-Landín, A., Merchán-García, W., \& GabrielOrtega, J. (2020). Los bioestimulantes: Una innovación en la agricultura para el cultivo del café (Coffea arabica L). Journal of the Selva Andina Research Society, 11(1), 18-28.

Veeramachaneni, S., \& Ramachandrudu, K. (2020). Changes in growth, microbial and enzyme activities in oil palm nursery in response to bioinoculants and chemical fertilizers. Archives of Agronomy and Soil Science, 66(4), 545-558. 
Vergara, C., Araujo, K., de Souza, S.R., Schultz, N., Saggin-Júnior, O.J., Sperandio, M., \& Zilli, J.E. (2019). Plant-mycorrhizal fungi interaction and response to inoculation with different growth-promoting fungi. Pesquisa Agropecuária Brasileira, 54, e25140.

Vieira, L.C., da Silva, D.K., da Silva, I.R., Gonçalves, C.M., de Assis, D.M., Oehl, F., \& da Silva, G.A.
(2019). Ecological aspects of arbuscular mycorrhizal fungal communities in different habitat types of a Brazilian mountainous area. Ecological Research, 34(1), 182-192.

Youkhana, A.H., \& Idol, T.W. (2011). Growth, yield and value of managed coffee agroecosystem in Hawaii. Pacific Agriculture and Natural Resources, 2, 12-19. 